\title{
Absence of Signs or Symptoms
}

National Cancer Institute

\section{Source}

National Cancer Institute. Absence of Signs or Symptoms. NCI Thesaurus. Code

C106101.

Absence of detectable signs or symptoms. 